\title{
Bio-Plastics - An Alternative to Petroleum Based Plastics
}

\author{
P. Prasteen ${ }^{1}$, Y. Thushyanthy ${ }^{2}$, T. Mikunthan ${ }^{3}$, M. Prabhaharan ${ }^{4}$ \\ Department of Agricultural Engineering, Faculty of Agriculture, University of Jaffna, Kilinochchi, Sri Lanka
}

*Corresponding Author: Y. Thushyanthy, Department of Agricultural Engineering, Faculty of Agriculture, University of Jaffna, Kilinochchi, Sri Lanka

\begin{abstract}
The environmental crises arising from the use of petroleum based non-degradable plastics led the globe to find alternatives. Biomaterial based plastic is one such alternative. This study aimed to produce biomaterial based plastic from corn starch (Cs) and gelatin (Ge) with the addition of glycerol (Gy) and mixture of vinegar and water and to determine the effect of the amount of Gy on the properties of plastics produced using Cs and Ge separately. For this purpose, six treatments were carried out by mixing Cs and Ge separately with Gy at three weight ratios (Cs:Gy and Ge:Gy), keeping the amount of Cs or Ge constant, while changing the amount of Gy such as; 1:4, 1:3 and 1:2. For each treatment, vinegar and water mixture $(1: 12, v / v)$ was added at the weight ratio of 4:13 (Cs or Ge: water and vinegar mixture). After mixing all ingredients, the mixture was heated while stirring at $80{ }^{\circ} \mathrm{C}$ until a semisolid mass is formed. Then the mass was spread out as a thin sheet on an aluminum foil and dried at $80{ }^{\circ} \mathrm{C}$ for $24 \mathrm{~h}$ in a hot air oven. The properties of produced plastic such as absorption of moisture, firmness, burning test, maximum elongation and thermoplastic natures of the produced plastics were tested using standard methods. Moisture absorption was determined by the percentage of weight change by moisture absorption by allowing the dried sheets to expose to the environment for six hours. The sheet produced by Cs and Gy with the ratio of 1:4 absorbed highest percentage of moisture $(1.22-2.14 \%)$ with time compared to other five treatments $(0.03-0.93 \%)$. Anyhow, there were no significant differences in the moisture absorption property among these six treatments. All the treatments with Gs and Gy showed a dark orange to yellow color flame with increasing speed of burning with increasing the amount of Gy. Among the six treatments, the treatment with Ge and Gy at the ratio of 1:4 exhibited highest firmness, while Cs: Gy at the ratio of 1:4 exhibited the lowest firmness, which could be attributed to the presence of gelatin. Further, the above two treatments showed maximum elongation, however, these are not significant $(p>0.05)$ between them. Thermo-plastic nature was not retained by the sheets produced by all treatments up to $120^{\circ} \mathrm{C}$. This study clearly revealed that Gy act as plasticizer; however, this plastic nature is influenced by other compounds as well. Furthermore, all sheets produced using Ge and Gy showed more flexibility compared to the Cs and Gy treatments because of the more flexible nature of the gelatin. Therefore, it can be concluded that there is a possibility to produce plastics from the above biomaterials as the raw materials and this will help mitigate the environmental issues. Further research need to be carried out to determine their durability and marketability.
\end{abstract}

Keywords: Bioplastic, cornstarch, gelatin, glycerol, plasticizer

\section{INTRODUCTION}

Population growth has dramatically increased the usage of different types of packaging materials which are including metals, glass, wood, paper and plastics or combination of more than one material as combinations to fulfill the necessities of human [1].Thereby plastics have now become essential materials, and the demand is frequently increasing due to their various and attractive usages in household and industries. These activities thus increasing the generation of wastes secondarily which pretense a very severe environmental challenge because of their enormous quantity and disposal problem as thermoplastics do not biodegrade for a very long time [2]. One of the most common wastes generated is the petroleum-based bags and/or plastic containers, which are the most common packaging materials commonly used in all around the world.

Generally these non-biodegradable packaging materials were discarded after use and end up in landfills which will generate pollution [3].Over the past century human society with most progresses have been facilitated by the use of these plastics in their routine life. Plastics are composed of a complex of molecular monomers bound together to form macromolecules. Today, more than twenty different major types of plastics are in use all over world [4]. Although plastics have been in the 
public eye recently for potentially dangerous human exposure to toxic constituents such as bisphenol A (BPA) and di-(2-ethylhexyl)phthalate (DEHP) [5], their beneficial effect on society is incontrovertible and demonstrated best by their medical uses and applications in public health.

Anyhow still there is no any reduction in the usage of plastics because of their cost-effective, require little energy to produce, lightweight and biocompatible and also can be soft, transparent, flexible[6, 7].

There are four major possibilities for disposal of plastics: land filling, incineration, recycling, and biodegradation. All plastics can be discarded in landfills or incinerated [6,8]. But, landfills need space. The second preference, incineration, yields some of the energy from plastic production but is known to produce adverse environmental and health effects [6]. Many plastics can be recycled, and some of the materials used to make plastics can be recovered. However, this method is not fully applied, due to complications with the collection and sorting of plastic waste [8]. Finally, such polymers are designed to biodegrade, thereby avoiding long-term environmental damage from pollution [9]. Though, many biodegradable plastics may not biodegrade promptly enough under ambient environmental conditions to prevent accumulation from continuous inputs [6]. Disposal of plastics in landfills eventually is unsustainable and reduces land resources which fit for other uses of higher societal value. Incineration yields the release of carbon dioxide, a greenhouse gas [6], and of other air pollutants, including carcinogenic polycyclic aromatic hydrocarbons (PAHs) [10] and dioxins [6].

At the same time extensive use of plastics facilitates continuous contact of these materials with the human body with daily exposure to ingredients in plastics [11]. So this is the time to reconsideration of the current management model of the production and disposal of plastics and to move towards a model that reflects the entire life-cycle of these abundant, essential materials.

As the level of environmental consciousness increases, public sector or industrialized sector starts to work on some biomaterials as the substitution of petroleum-based or plastic materials [1]. Increasing consumption of biodegradable plastics $\mathrm{c}$ an diminish the carbon footprint, pollution risks, and greenhouse gas emissions from polymer usage; however, it can do so only if these alternatives are made from non-fossil resources using renewable energy[6].

Further the development of bioplastic materials can be performed from starchy and protein components may become an alternative for the non-degradable materials. Moreover, the presence of bioplastic can produce degradable materials with a higher durability. Besides, through the production bioplastic contained materials can manage the plant waste or plant residues in an efficient manner. This study was focused in the production of bioplastic materials from corn starch and gelatin with the addition of glycerol and mixture of vinegar and water. At the same time the effect of the amount of glycerol on the properties of plastics produced using corn starch and gelatin separately also was determined to explore their capacity as an alternative source to non-degradable plastics.

\section{MATERials AND Methods}

\subsection{Preparation of Raw Materials}

Materials which were used for the production of bioplastic were corn starch, gelatin, glycerol with $99.5 \%$ concentration distilled water and vinegar.

\subsection{Production of Bioplastic}

The selected raw materials for the production of bioplastics were quantified based on their weight percentage. Two sets of bioplastics were prepared by using corn starch and gelatin separately. First, appropriate amounts of materials were taken based on their weight ratio as shown in the table 1 . Secondly, those selected materials were mixed together in room temperature to prepare the following mixtures.

Table1. Composition of different types of mixtures by weight basis

\begin{tabular}{|l|l|l|l|}
\hline & Treatment -1 (T1) & Treatment- 2 (T2) & Treatment -3 (T3) \\
\hline Corn starch : Glycerol : Vinegar + Water & $1: 4: 13$ & $1: 3: 13$ & $1: 2: 13$ \\
\hline Vinegar & $5 \mathrm{~mL}$ & $5 \mathrm{~mL}$ & $5 \mathrm{~mL}$ \\
\hline Water & $60 \mathrm{~mL}$ & $60 \mathrm{~mL}$ & $60 \mathrm{~mL}$ \\
\hline & Treatment -4 (T4) & Treatment -5 (T5) & Treatment -6 (T6) \\
\hline
\end{tabular}

International Journal of Research Studies in Agricultural Sciences (IJRSAS) 


\begin{tabular}{|l|l|l|l|}
\hline Gelatin : Glycerol : Vinegar + Water & $1: 4: 13$ & $1: 3: 13$ & $1: 2: 13$ \\
\hline Vinegar & $5 \mathrm{~mL}$ & $5 \mathrm{~mL}$ & $5 \mathrm{~mL}$ \\
\hline Water & $60 \mathrm{~mL}$ & $60 \mathrm{~mL}$ & $60 \mathrm{~mL}$ \\
\hline
\end{tabular}

Mixture 1: Corn starch, glycerol and mixture of distilled water and vinegar (1:12, v/v) Mixture 2: Gelatin, glycerol and mixture of distilled water and vinegar $(1: 12, \mathrm{v} / \mathrm{v})$

Then the mixtures were stirred continuously and heated on hot plate at $80{ }^{\circ} \mathrm{C}$ temperature until obtain sticky gel texture [3]. The produced gel was spread evenly on an aluminum foil to get a thin sheet with a thickness of $2 \mathrm{~mm}$. Then, the spread of bioplastic sheets were dried in a hot air oven at $80{ }^{\circ} \mathrm{C}$ temperature for the time of 24 hours [12]. The purpose of drying the spread of bioplastic was to enable the process of spread removal from aluminum foil easier. After that, the spread of bioplastic was removed from aluminum foil and further involved into several tests.

\subsection{Experimental Setup}

There were six different treatments set up were prepared by incorporating gelatin and corn starch as given in the table 1. Each treatment was allowed for moisture absorption test, burning test, break point investigation and bore test for firmness and investigation for thermo plastic nature to check its plastic nature.

\subsection{Testing of Bioplastic}

\subsubsection{Moisture absorption test}

After drying with overnight period, initial weight of each sheet was measured as first. These dried sheets of bioplastic were exposed to outer environment for six hours of period. Weight changes of bioplastic sheets were measured with each one hour interval.

\subsubsection{Burning test}

Bioplastic produced from each treatment was burnt by using coconut oil lamp to observe color of flame and speed of burning [12]

\subsubsection{Maximum Elongation / Break point}

Strip of each bioplastic sheet was obtained with uniform dimension to eliminate the influence of other factors on elongation. Elongation was taken up to its breakpoint and the measurement was taken by using measuring tape.

\subsubsection{Firmness test}

Bioplastics from each treatment were tested to evaluate their firmness by bore test with the highest pressure of 2.0 Mpa with a force of $221.31 \mathrm{~N}$

\subsubsection{Test as thermo plastic}

Each treatment was exposed to different temperature range of $60-120{ }^{\circ} \mathrm{C}$. The changes due to exposed temperature were investigated by visual observation and feel method by allowing them for overnight in a hot air oven.

\subsubsection{Statistical analysis}

Each treatment was duplicated to check its accuracy statistically with a SAS 9.0 package with CRD test and DUNCAN mean group.

\section{RESULTS AND DISCUSSION}

\subsection{Moisture Absorption Test}

The Prepared bio plastic sheets from each treatment was allowed for moisture absorption test after getting complete drying with hot air oven for a condition of $70{ }^{\circ} \mathrm{C}$ for 24 hours. After complete oven drying, initial weight of each treatment was recorded; these were 14.20, 13.80, 13.19, 13.07, $13.42 \&$ $12.33 \mathrm{~g}$ which were consisted by $\mathrm{T} 1, \mathrm{~T} 2, \mathrm{~T} 3, \mathrm{~T} 4$, and $\mathrm{T} 5 \& \mathrm{~T} 6$ respectively. Then weight change percentage was estimated by exposing each treatment to outer environment with taking weight measurement for one hour interval. 
Table 2. Weight change percentage due to moisture influence

\begin{tabular}{|l|l|l|l|l|l|l|}
\hline \multirow{2}{*}{ Treatment } & \multicolumn{7}{|c|}{ Weight change percentage (\%) } \\
\cline { 2 - 7 } & $9.30 \mathrm{am}$ & $10.30 \mathrm{am}$ & $11.30 \mathrm{am}$ & $12.30 \mathrm{pm}$ & $1.30 \mathrm{pm}$ & $2.30 \mathrm{pm}$ \\
\hline T1 & 1.217 & 1.739 & 2.139 & 2.006 & 1.307 & 1.290 \\
\hline T2 & 0.169 & 0.405 & 0.709 & 0.567 & 0.298 & 0.153 \\
\hline T3 & 0.036 & 0.414 & 0.934 & 0.320 & 0.595 & 0.099 \\
\hline T4 & 0.549 & 0.584 & 0.669 & 0.439 & 0.088 & 0.014 \\
\hline T5 & 0.915 & 1.079 & 1.345 & 1.198 & 0.446 & 0.156 \\
\hline T6 & 0.378 & 0.343 & 0.908 & 0.699 & 0.112 & 0.037 \\
\hline
\end{tabular}

With one our interval according to the table2, the treatment T1 (sheet produced by Corn starch and Glycerol with the ratio of $1: 4)$ had shown highest weight change $(1.22-2.14 \%)$ due to higher moisture absorption with time compared to other five treatments $(0.03-0.93 \%)$. Anyhow, there were no significant differences in the moisture absorption property among these six treatments. So moisture absorption pattern is slightly changed by the influence of exposed environmental temperature. Keeping this product in dry condition will increase the shelf life of the product which is produced with corn starch and gelatin

\subsection{Burning Test}

During burning with coconut oil lamp, color of flame and speed of burning were observed. T1, T2 and T3 which have the composition of corn starch with different percentage of glycerol had shown a flame in dark orange - yellow color as indicated in the plate 1A. But speed of burning is increased with increasing glycerol composition among the treatments $(\mathrm{T} 1>\mathrm{T} 2>\mathrm{T} 3)$ with corn starch. But these effects couldn't observe in the set of treatments T4, T5 and T6 which have the composition of gelatin. These treatments had shown melting ability as shown in the plate $1 \mathrm{~B}$.
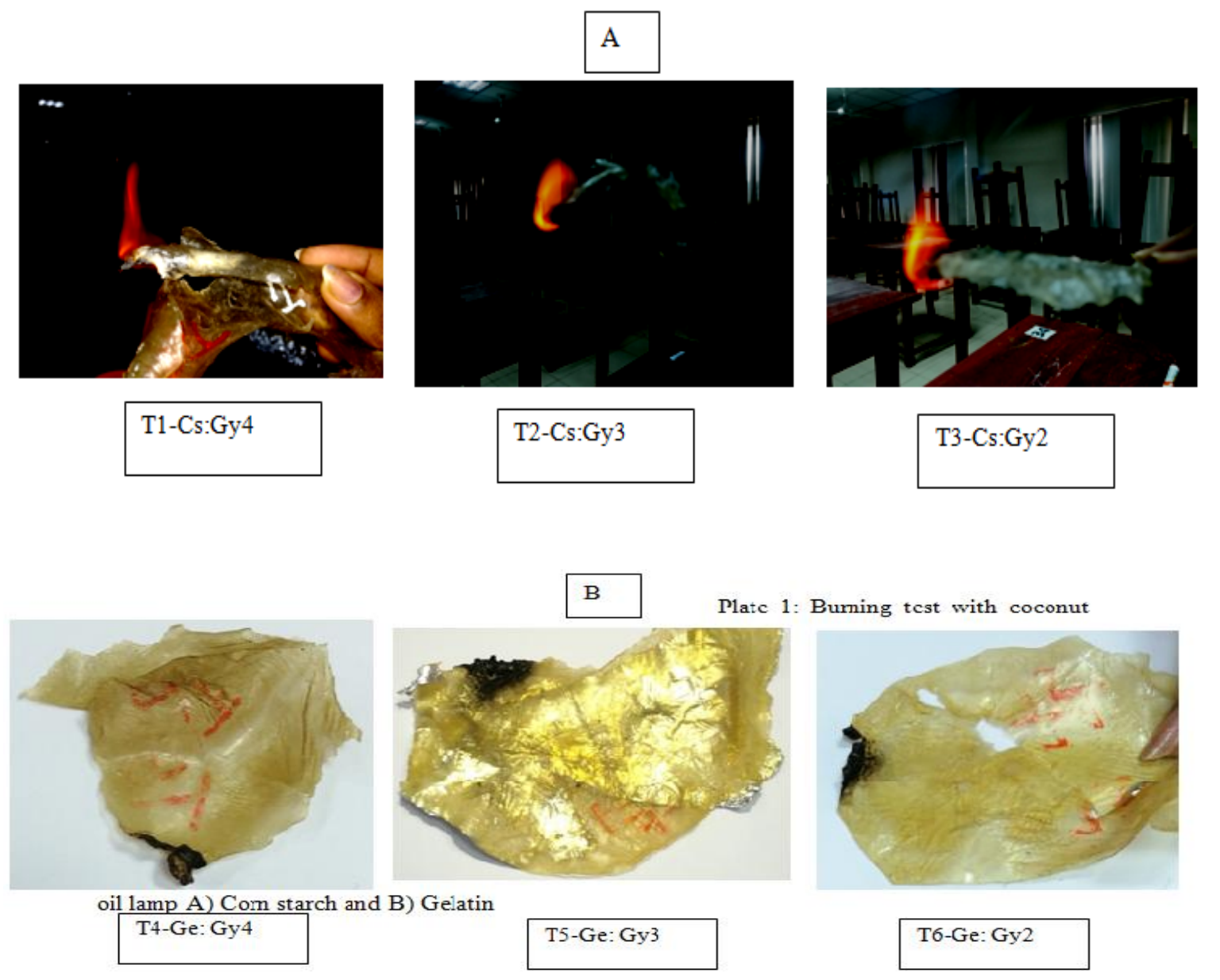


\subsection{Firmness test}

Bioplastics from each treatment were tested to evaluate their firmness by bore test with the highest pressure of 2.0 Mpa with a force of 221.31 N. The effect of given force against their firmness was checked. Bore marks were permanently identified only in the treatment of $\mathrm{T} 1$ which has the composition of corn starch and highest ratio of glycerol. T4 which has the composition of gelatin didn't have any marks under same force condition even it has highest glycerol ratio.

\subsection{Maximum Elongation Test / Break Point Test}

Maximum elongation is obtained by T1 and T4 which have the composition of corn starch and gelatin respectively with highest glycerol ratio as shown in the figure 1 . Other treatments are shown lesser effect on elongation and this elongation rate is reduced with decreasing glycerol ratio because glycerol can act as a plasticizer $[13,14]$. Anyhow gelatin has highest elongation percentage than corn starch. Treatment T4 has highest significant than other treatments. At the same time both T1 and T4 have same ratio of glycerol, anyhow the significant effect is consisted by $\mathrm{T} 4$ than $\mathrm{T} 1$ due to gelatin composition at $95 \%$ confident interval. Means marked with same letter are not significantly different at $\alpha=0.05$

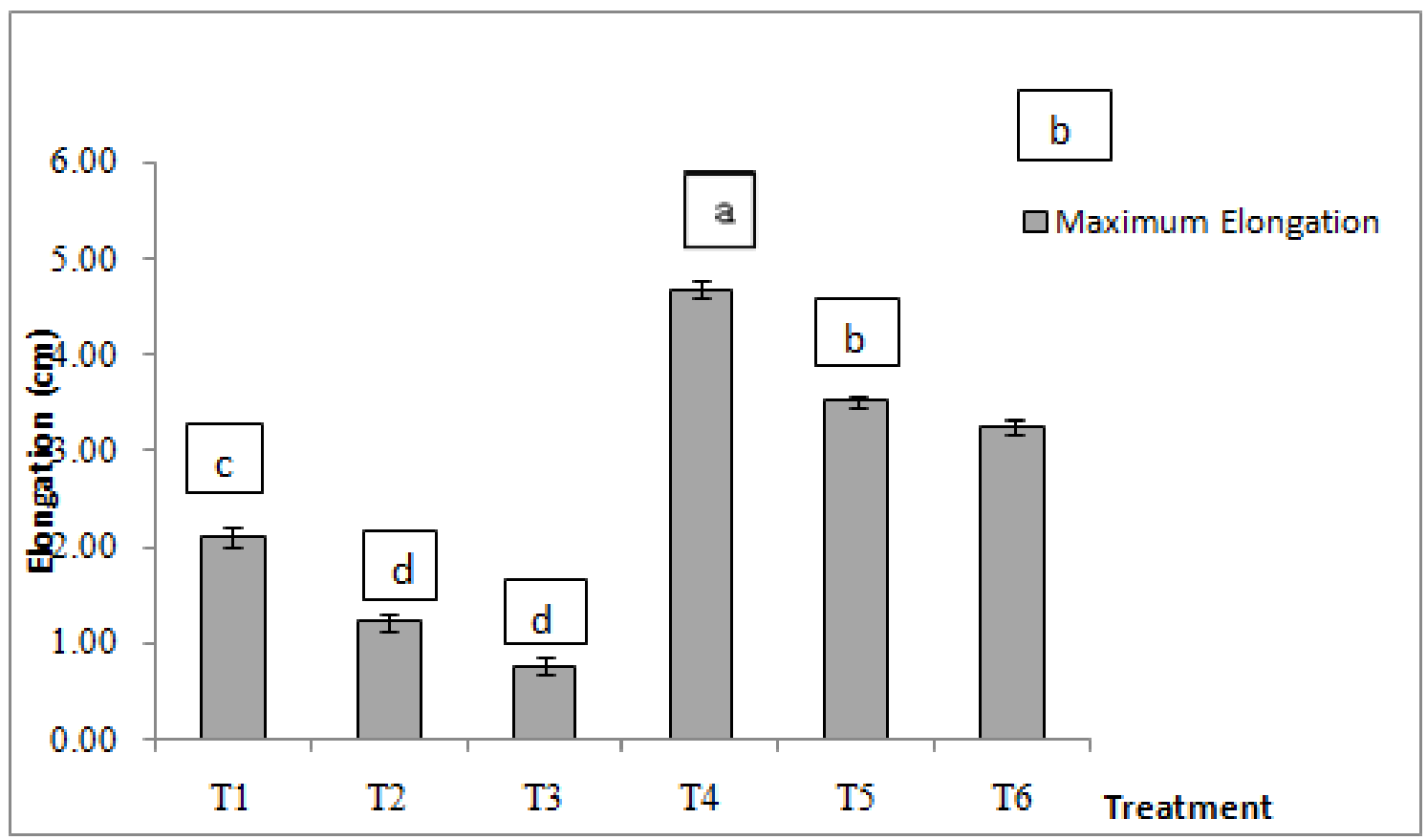

Figure1. Maximum elongation with different treatment compositions

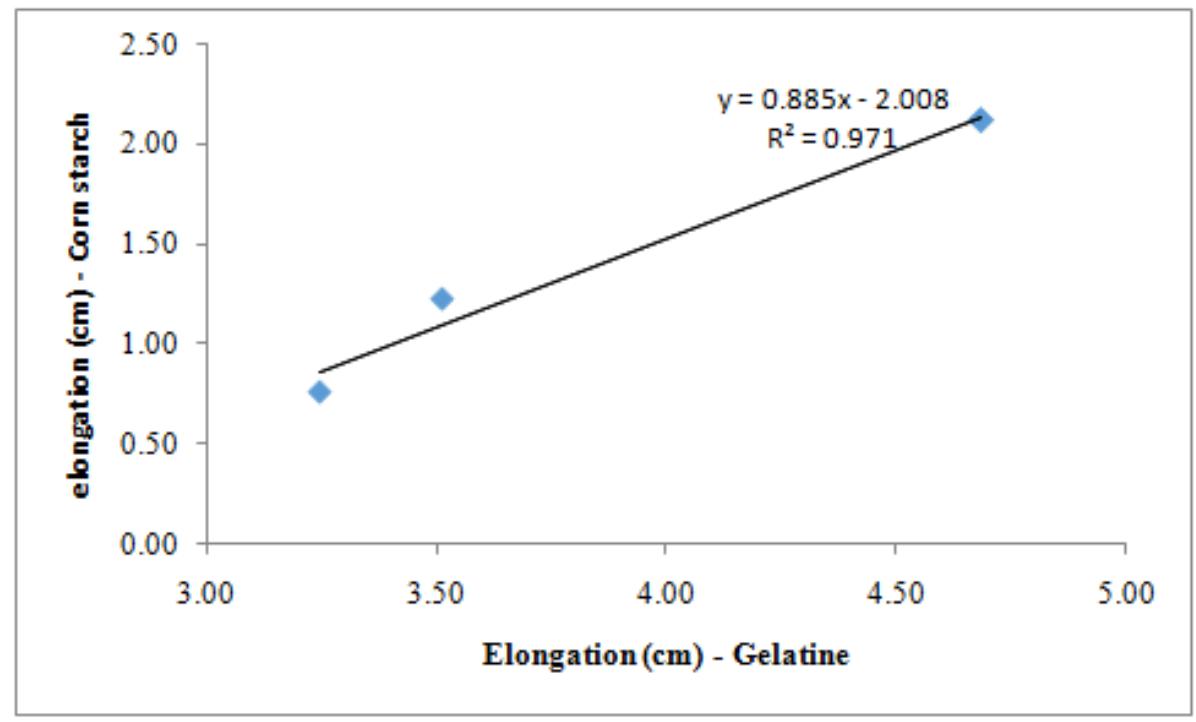

Figure2. Degree of elongation (maximum) correlation between gelatin and corn starch 
Figure 2 shows the degree of correlation between the elongation of bioplastics which are made from corn starch and gelatin. Based on the given figure 3, both don't have that much of correlation in between them.

\subsection{Crack Test}

While drop $15 \mathrm{~kg}$ weight from $1 \mathrm{~m}$ height on to the each treatment didn't exhibit any cracks and no more changes in their structure and shape.

\subsection{Test as Thermo Plastic}

Up to $110^{\circ} \mathrm{C}$ there no any external changes were observed in each treatment. But when the treatments were in $120{ }^{\circ} \mathrm{C}$, treatments (T4, T5 and T6) which contains gelatin as major composition had shown too much of flexibility and softness when compare with other treatments of T1, T2 and T3 those contains corn starch in their composition.

\section{CONCLUSiON}

This study showed that bioplastic produced from different compositions with different ratios were tested with such tests. Moisture absorption is changed with environmental temperature but the changes obtained were not significant. Glycerol is having the plasticizing ability thereby plastic nature among treatments were $\mathrm{T} 4>\mathrm{T} 5>\mathrm{T} 6$ in gelatin composition and $\mathrm{T} 1>\mathrm{T} 2>\mathrm{T} 3$ in corn starch composition. Anyhow plastic character is highest for T4 than T1 this is because of the gelatin. Gelatin has more flexible nature than corn starch. Due to this effect, maximum firmness and maximum elongation are composed by $\mathrm{T} 4$ which has gelatin and highest ratio of glycerol. The treatments with corn starch can have a quick burning ability than gelatin. According to these effects, the obtained bioplastics can be used as a substitution for non-degradable plastics. This result is also supported by thermoplastic nature which is ensured by the thermo plastic test. Therefore, it can be concluded that there is a possibility to produce plastics from the above biomaterials as the raw materials and this will help mitigate the environmental issues. Further research need to be carried out to determine their durability and marketability.

\section{REFERENCES}

[1]. Song, J., et al., Biodegradable and compostable alternatives to conventional plastics. Philosophical Transactions of the Royal Society of London B: Biological Sciences, 2009. 364(1526): p. 2127-2139.

[2]. Patni, N., et al., Alternate strategies for conversion of waste plastic to fuels. ISRN Renewable Energy, 2013. 2013.

[3]. Liew, K.C. and L.K. Khor, Effect of different ratios of bioplastic to newspaper pulp fibres on the weight loss of bioplastic pot. Journal of King Saud University-Engineering Sciences, 2015. 27(2): p. 137-141.

[4]. Plastic-Europe, A., Analysis of Plastics Production, Demand and Recovery in Europe. 2006, Association of Plastic Manufacturers: Brussels.

[5]. Halden, R.U., Plastics and health risks. Annual review of public health, 2010. 31: p. 179-194.

[6]. North, E.J. and R.U. Halden, Plastics and environmental health: the road ahead. Reviews on environmental health, 2013. 28(1): p. 1-8.

[7]. Irimia-Vladu, M., "Green" electronics: biodegradable and biocompatible materials and devices for sustainable future. Chemical Society Reviews, 2014. 43(2): p. 588-610.

[8]. Hopewell, J., R. Dvorak, and E. Kosior, Plastics recycling: challenges and opportunities. Philosophical Transactions of the Royal Society of London B: Biological Sciences, 2009. 364(1526): p. 2115-2126.

[9]. Shah, A.A., et al., Biological degradation of plastics: a comprehensive review. Biotechnology advances, 2008. 26(3): p. 246-265.

[10]. Shemwell, B.E. and Y.A. Levendis, Particulates generated from combustion of polymers (plastics). Journal of the Air \& Waste Management Association, 2000. 50(1): p. 94-102.

[11]. Calafat, A.M., et al., Urinary concentrations of bisphenol A and 4-nonylphenol in a human reference population. Environmental health perspectives, 2005. 113(4): p. 391.

[12]. Hossain, A.S., N.A. Ibrahim, and M.S. AlEissa, Nano-cellulose derived bioplastic biomaterial data for vehicle bio-bumper from banana peel waste biomass. Data in brief, 2016. 8: p. 286-294.

[13]. Ferreira, S.P., W.A. Ruiz, and A. Gaspar-Cunha, Rheological and thermal characteristics of wheat gluten biopolymers plasticized with glycerol. Química Nova, 2012. 35(4): p. 719-722.

International Journal of Research Studies in Agricultural Sciences (IJRSAS) 
[14]. Lopez-Gil, A., M. Rodriguez-Perez, and J.A. De Saja, Strategies to improve the mechanical properties of starch-based materials: plasticization and natural fibers reinforcement. Polímeros, 2014. 24(SPE): p. 3642.

Citation: P. Prasteen, et.al, "Bio-Plastics - An Alternative to Petroleum Based Plastics ", International Journal of Research Studies in Agricultural Sciences, vol. 4, no. 1, p. -0107, 2018. http://dx.doi.org/ 10.20431/2454-6224.0401001

Copyright: () 2018 Authors. This is an open-access article distributed under the terms of the Creative Commons Attribution License, which permits unrestricted use, distribution, and reproduction in any medium, provided the original author and source are credited. 